\section{Residential Landscapes, Homeowner Attitudes, and Water-wise Choices in New Mexico}

\author{
Brian H. Hurd ${ }^{1}$, Rolston St. Hilaire ${ }^{2}$, and John M. White ${ }^{3}$
}

ADDITIONAL INDEX wORDs. water conservation, xeriscape, arid landscape, landscape preferences, urban water use

SummARY. Residential landscapes are responsible for a large share of the water use of New Mexico communities. Water conservation plans and programs are being promulgated throughout New Mexico and the western U.S. as concern grows over the sufficiency and variability of present supplies, sustainability of current population growth rates, and desire for enhanced economic development. Household attitudes, choices, and behaviors ultimately underlie the success and performance of community water conservation programs. Homeowners in three New Mexico cities were surveyed concerning their attitudes and behavior toward water use, water conservation, and residential landscapes. Findings suggest that New Mexico's homeowners are mindful of the water resource challenges faced by communities, and are prepared to shoulder responsibility for stewarding the state's water resources. There is broad community support to limit traditional turfgrasses [e.g., kentucky bluegrass (Poa pratensis)] and to increase the areas planted to native, natural, and water-conserving landscapes; for example, $92 \%$ favored limiting turfgrass to less than $25 \%$ of the area around public buildings. Evidence showing that $40 \%$ are not "content" with their current landscape suggests that significant impediments remain and limit still greater adoption of water-conserving landscapes and subsequent potential for increased household water savings.

$\mathrm{C}$ ommunities throughout New Mexico and the western United States are challenged by increasingly scarce water supplies and desire for continued economic development. Responses by many municipal water agencies often include municipal water conservation programs that aim to reduce per capita water use. Program

Acknowledgments. We would like to thank New Mexico State University's Agricultural Experiment Station for continued research support, and the Rio Grande Basin Initiative, a joint research program of New Mexico State University (NMSU) and Texas A\&M University, for funding this project. I would like to acknowledge the following individuals for their assistance during the course of this project: Josh Smith and Sylvia Beuhler, for their research assistance and help in coordinating the survey; John White, Rhonda Skaggs, and Bernd Leinauer for technical assistance and review; Joshua Rosenblatt of the City of Las Cruces for his enthusiasm and stimulating insights; Craig Runyan and Leeann DeMouche for their overall project leadership and support; and, finally, the survey participants and water conservation staff from the cities of Albuquerque, Santa $\mathrm{Fe}$, and Las Cruces, N.M.

${ }^{1}$ Assistant Professor, Department of Agricultural Economics and Agricultural Business, MSC 3169, Box 30003, New Mexico State University, Las Cruces, NM 88003-8003. To whom reprint requests should be addressed:phone: (505) 646-2674; fax: (505) 646-3522; e-mail: bhhurd@nmsu.edu

${ }^{2}$ Associate Professor, Department of Plant and Environmental Sciences, New Mexico State University, Las Cruces.

${ }^{3}$ Doña Ana County Program Director, Doña Ana County Extension Office, New Mexico State University, Las Cruces. elements often include efforts to raise water resource awareness; economic incentives, such as turfgrass rebate programs and conservation water rates; and promoting the adoption of watersaving technologies, such as monitored irrigation and drip systems. As public resources are directed into such programs, concerns are raised about their effectiveness and performance. Assessments of public attitudes and the barriers to changing behavior can regions of southern Nevada. ${ }^{2}$

${ }^{2}$ Source: (Sovocool, 2005)

$\mathrm{y} 1 \mathrm{gal} / \mathrm{ft}^{2}=40.7458 \mathrm{~L} \cdot \mathrm{m}^{-2}$ provide both quantitative and qualitative measures of conservation program impacts and effectiveness and are key concerns of this study.

This paper examines homeowner attitudes and perspectives toward water and residential landscapes, identification of preferred landscapes, and the barriers that impede transition toward water-wise landscapes.

URBAN LANDSCAPES, WATER USE, ATTITUDES, AND BEHAVIOR. Watering residential landscapes is the single greatest household use of water in arid and semi-arid cities. Often accounting for more than $50 \%$ of household annual water consumption, changes in landscape watering can yield potentially significant water savings. Estimates of water savings range from $35 \%$ to $75 \%$ of current per capita water use, based on a typical home with a traditional bluegrass-type landscape, as shown in Table 1 (Ferguson, 1987; Knopf, 2003; Sovocool, 2005).

Along the Rio Grande, throughout the arid western U.S., and even in increasingly water-scarce areas in the eastern U.S., water-intensive lawn landscapes are increasingly yielding to more water-efficient and climate-appropriate landscapes. Acceptance of water-conserving, xeriscape (Denver Water Board, Denver) yards is growing; for example, Spinti et al. (2004) found an increasing acceptance of the aesthetics of desert-type landscapes (e.g., $>80 \%$ for use in front yards and $>56 \%$ in back yards in their sample of Las Cruces, N.M., homeowners). In spite of this level of acceptance, actual adoption rates were, however, lower

Table 1 . The estimated annual vegetative water requirements of xeriscape and turfgrass landscapes and their water savings potential are compared for the desert

\begin{tabular}{lc}
\hline Landscape type & Annual water needs $\left(\mathrm{gal} / \mathrm{ft}^{2}\right)^{\mathrm{y}}$ \\
\hline Newly planted xeriscape & 17 \\
Mature xeriscape with 50\% coverage & 22 \\
Densely planted with $100 \%$ coverage & 25 \\
Lawn & 79 \\
Potential water savings & $54(\sim 68 \%$ over \\
& traditional lawn $)$ \\
\hline
\end{tabular}

\begin{tabular}{llll}
\hline $\begin{array}{l}\text { Units } \\
\text { To convert U.S. to SI, } \\
\text { multiply by }\end{array}$ & U.S. unit & SI unit & $\begin{array}{l}\text { To convert SI to U.S., } \\
\text { multiply by }\end{array}$ \\
\hline 0.3048 & $\mathrm{ft}$ & $\mathrm{m}$ & 3.2808 \\
0.0929 & $\mathrm{ft}^{2}$ & $\mathrm{~m}^{2}$ & 10.7639 \\
3.7854 & $\mathrm{gal}$ & $\mathrm{L}$ & 0.2642 \\
40.7458 & $\mathrm{gal} / \mathrm{ft}^{2}$ & $\mathrm{~L} \cdot \mathrm{m}^{-2}$ & 0.0245
\end{tabular}


by $25 \%$ to $30 \%$, suggesting that there may be significant barriers that are impeding adoption.

Water-conserving landscape choices can be a fundamental component of urban water conservation. Such landscape choices are not, however, sufficient for achieving successful water savings. Achieving significant water savings from landscape changes depends on several factors besides vegetation cover. Irrigation technology and capability of homeowners to manage also drive system efficiency. For example, research at the University of CaliforniaRiverside Turfgrass Research Facility has shown that two-thirds of the water savings from municipal turfgrass rebate programs is the result of upgraded and more efficient irrigation systems, while the remaining one-third is attributable to the switch from turfgrass to xeriscape (Addink, 2005).

Effective municipal water conservation programs will achieve significant per capita water savings by identifying and addressing the key triggers that alter household behavior. There are many potential triggers affecting landscape choices and irrigation management. Key elements of water conservation programs that may trigger landscape changes can include both economic incentives and non-economic strategies. Economic incentives include changes to water rate schedules that increase costs with increasingly higher levels of water use, and xeriscape incentive programs that, for example, offer cash payments to eliminate traditional turfgrass lawns.

Non-economic strategies include strategies that raise awareness, develop attitudes of responsibility toward water resources, enhance xeriscaping of community and public landscapes, and increase access to information and guidance on landscape conversions. Transitions toward water-conserving landscapes can be induced or hindered by desires for consistency with neighboring landscapes, cultural constraints (e.g., preconceptions of residential landscape or familiarity and comfort with traditional turfgrass lawns), and ultimately by access to and availability of sufficient time and money.

\section{Methods, data, and analysis}

Adequate and representative data are central to the identification and assessment of homeowner attitudes and behaviors. A mail survey approach was selected as the most reliable, expedient, and cost-efficient means of communicating with homeowners and obtaining their responses. of questions about their landscape attitudes and choices, moving from general aspects to more specific. The survey contained four sections:

1 . Water use at your home

2. Your home's landscape

3. Landscape types, water use, and upkeep costs

4. About you and your family

The central protocols of Dillman's tailored design method (TDM) for mail surveys (Dillman, 2000) were followed. A cover letter described the purpose of the study and stressed the importance of each and every response. Reminder postcards were sent 1 week following the initial mailing, and 2 weeks after that, non-respondents were sent a second survey and cover letter.

More than 400 residential homeowners in each of three New Mexico cities-Albuquerque, Santa Fe, and Las Cruces-were randomly sampled using records from the municipal utility of each city. These records generally contain a representative cross-section of households within the respective communities and were filtered to identify only single-family dwellings.

In May 2004, 1216 surveys were mailed to approximately 400 residents in each of the three cities. The final survey returns were recorded in late Aug. 2004. In total, 423 surveys were returned, which after adjusting for undeliverable addresses, resulted in a response rate of $36.7 \%$, as shown in Table 2 (Hurd and Smith, 2005). The data were digitized, quality checked, and analyzed using SAS (version 9.1; SAS Institute, Cary, N.C.).

\section{Results and discussion}

Attitudes toward WATER ReSOURCES. Two general questions con-
The survey contained a series

cerning community water resources were asked to gauge attitudes about community importance of water issues and perceived household responsibility for water conservation. The first measures a general attitude toward the overall significance that the homeowner assigns to water resources and its underlying importance to the community on a scale from 1 = "not very important" to $5=$ "one of the most important." The second measures the homeowner's perceived responsibility in conserving water resources, and indicates the attitude and relationship of the water user toward water resources and the role and services provided by water to the community.

Across all the cities, more than $72 \%$ of homeowners reported that water issues were "one of the most important" facing the state and its communities. There was some variation across communities, with the highest observed in Santa Fe where more than $85 \%$ of residents reported water issues as "among the most important" compared to $70 \%$ and $59 \%$ in Las Cruces and Albuquerque, respectively. These community differences, indicated in Fig. 1, are statistically significant at the $1 \%$ probability level using the chi-square test. With nearly three out of every four homeowners rating this at the highest level, there is, apparently, widespread awareness of water's importance to New Mexico community welfare.

In addition to "awareness," behavioral changes may also be conditioned by a perceived sense of responsibility to act morally. This is very important because it provides a basis for motivating water-use efficiency changes aside from economic self-interest. The importance for municipal conservation programs is underscored by the weight frequently given to non-economic conservation strategies and the political resistance toward raising utility rates to induce conservation.

Table 2. Response rate characteristics by city as determined by a 2004 survey of New Mexico homeowners regarding their attitudes and behavior toward water use/conservation and residential landscapes.

\begin{tabular}{lccccc}
\hline & Las Cruces & Albuquerque & Santa Fe & NA $^{\mathrm{z}}$ & Total \\
\hline & -10 & 400 & 406 & & 1216 \\
Mailed & 410 & 109 & 155 & 2 & 423 \\
Responses & 157 & 25 & 16 & & 63 \\
Undeliverable & 22 & $29.1 \%$ & $39.7 \%$ & & $36.7 \%$ \\
\hline
\end{tabular}

${ }^{2}$ Number of respondents who intentionally removed survey identification number. 
The measure of perceived responsibility of households for conserving water is illustrated in Fig. 2, and is somewhat less pronounced than "awareness." While only $37 \%$ of homeowners felt "very responsible," if the next category of "fairly responsible" is included, the total exceeds $75 \%$. This finding is potentially important because it indicates an apparent gap between "awareness" of importance and recognition of the household's role as a resource consumer and steward, and it suggests room for improvement through education and outreach strategies that can strengthen the association between resource use and user responsibility.

The pattern across communities is similar to the previous response with Santa Fe homeowners indicating the highest sense of responsibility, $48.3 \%$ and $35.5 \%$ for the highest two categories, respectively, and $83.8 \%$ combined. Perceived responsibility was a bit lower in Las Cruces and Albuquerque with $72.1 \%$ and $68.8 \%$, respectively, for the combined levels. These community differences are also statistically significant at the $1 \%$ probability level using the chi-square test. Curiously, less than $20 \%$ of Albuquerque homeowners assigned the highest level of responsibility, far lower than Las Cruces or Santa Fe, which indicated $38.4 \%$ and $48.3 \%$, respectively. Perhaps with the larger urban center there is a greater detachment from the resource base and lessidentification with household's role and impact in natural systems.

LANDSCAPE CHOICES, ATTITUDES, AND BARRIERS. One of the key areas in which aware and responsible homeowners can act to conserve water resources is to alter their outdoor water use, specifically regarding their landscape, methods of irrigation, and management. To assess acceptance and desirability of landscape changes that enhance water use efficiency, the survey identified current landscape conditions and factors affecting landscape choices. Questions were also asked to identify and characterize impediments to achieving desired changes. The findings to these questions are described below.

Homeowners were first asked to estimate the relative share of their landscape under various landscape types as shown in Table 3. The category of "rocks, gravel and bare soil" was most reported, with the highest share overall,

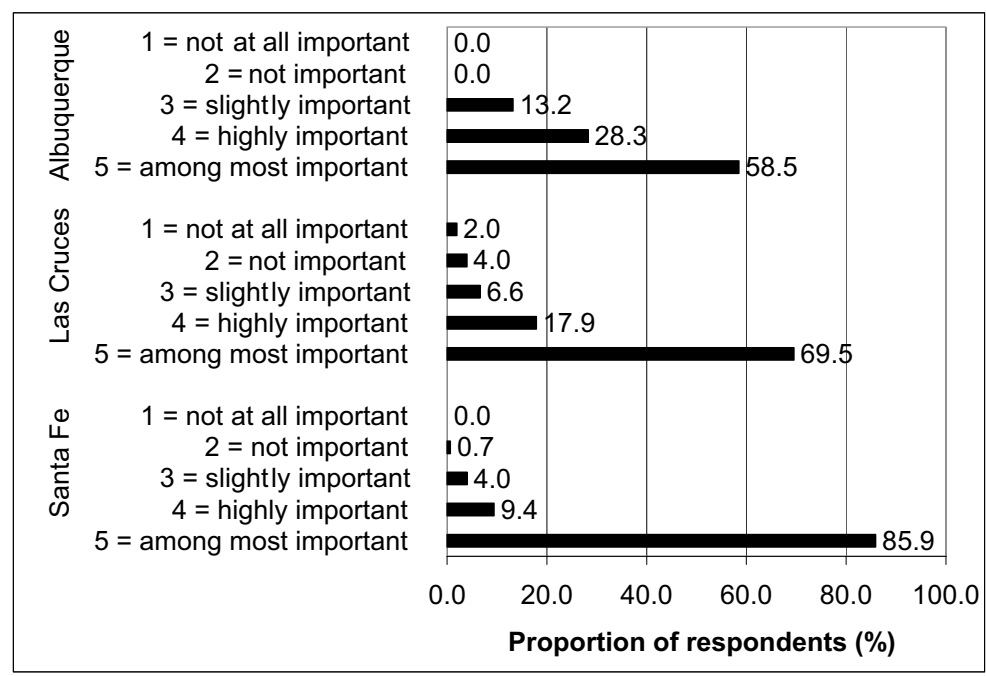

Fig. 1. The relative importance of water issues to the community as perceived by urban New Mexico homeowners reported in a 2004 survey of homeowners. Differences across cities are statistically significant at the $1 \%$ level $\left(\chi^{2}=39.0,8 \mathrm{df}\right)$.

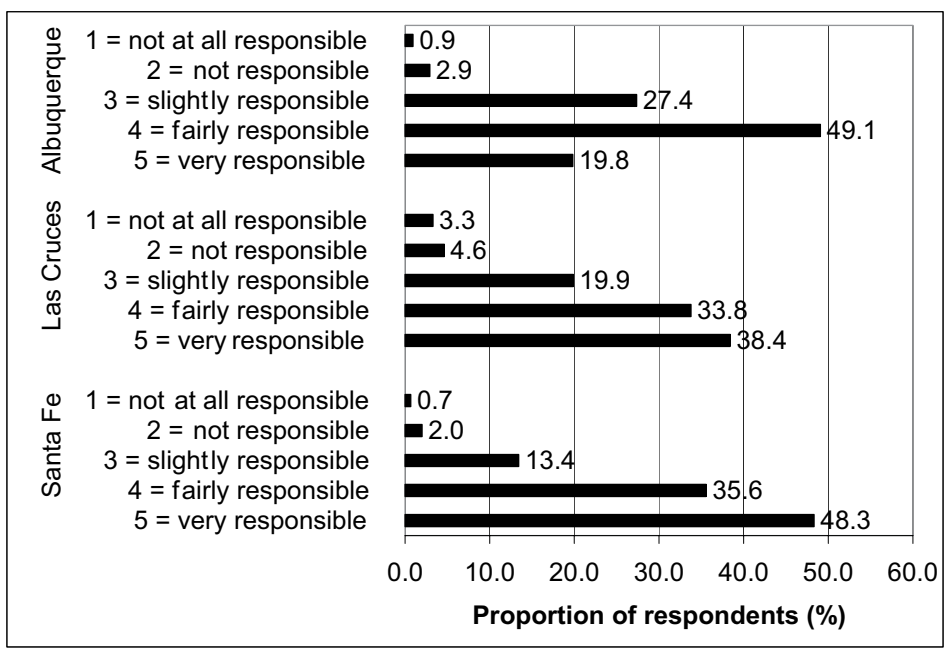

Fig. 2. The relative degree of household responsibility for water conservation as perceived by urban New Mexico homeowners reported in a 2004 survey of homeowners. Differences across cities are statistically significant at the $1 \%$ level $\left(\chi^{2}=29.3,8 \mathrm{df}\right)$.

Table 3. The landscape and vegetation types of urban New Mexican homes are reported in a 2004 survey of homeowners.

\begin{tabular}{|c|c|c|c|c|}
\hline Landscape type & Albuquerque & Las Cruces & Santa Fe & Overall \\
\hline Traditional-type lawn & 22.9 & 9.68 & 2.85 & 10.8 \\
\hline Water-conserving type lawn & 5.1 & 19.6 & 5.6 & 10.6 \\
\hline Traditional-type trees and shrubs & 9.0 & 11.8 & 9.3 & 10.1 \\
\hline Water-conserving type trees and shrubs & 8.3 & 9.9 & 13.3 & 10.7 \\
\hline Flowers and vegetable gardens & 6.1 & 6.5 & 8.6 & 7.1 \\
\hline Native/natural desert landscape & 15.5 & 8.0 & 30.8 & 18.2 \\
\hline Rocks, gravel, and bare soil & 33.5 & 37.6 & 29.5 & 33.6 \\
\hline Other & 1.5 & 2.2 & 2.1 & 2.0 \\
\hline
\end{tabular}

${ }^{2}$ Columns do not sum exactly to $100 \%$ due to rounding errors. 
with an average covering $33.6 \%$ of the landscapable area. Native desert landscape was second, averaging $18.2 \%$. Traditional lawn, water-conserving trees and shrubs, water-conserving type lawn, and traditional trees and shrubs each averaged $10 \%$ to $11 \%$, followed finally by gardens with $7.1 \%$. This pattern suggests a substantially diverse residential landscape mix in which "water-conserving" landscape types comprise more than two-thirds of the landscapable area.

Across the three communities there are interesting differences, such as the contrast in the amount of "traditional lawn" between Albuquerque and Santa Fe. With nearly 23\%, Albuquerque has the greatest share of landscapable area in traditional type water-intensive type lawns compared to fewer than 3\% in Santa Fe. Las Cruces, on the other hand, leads in terms of "water-conserving" type lawns with nearly $20 \%$ in this type of landscape. Climatic differences between the northern and southern regions of the state explain some of these differences, with the southern range better suited to warm season, drought-tolerant grasses such as bermudagrass (Cynodon dactylon). Combining both types of lawns, Las Cruces has the highest percentage of turfgrass landscape, close to $30 \%$, followed by Albuquerque with 28\%, and Santa Fe with 8.5\%. Santa Fe appears to make up for the difference in the amount of lawn with a much higher share of native or natural desert landscape, $31 \%$ compared to $16 \%$ and $8 \%$ in Albuquerque and Las Cruces, respectively.

Homeowner attitudes toward their existing landscape were also measured. Overall, more than 40\% expressed discontentment with their present landscape, with about $10 \%$ expressing a desire for "much less lawn." Santa Fe showed the greatest level of satisfaction with $61 \%$. This reflects the greater share of natural landscape and its inherent desirability by Santa Fe residents. Albuquerque and Las Cruces are strikingly similar in the extent that they may consider landscape changes. In both communities more than $40 \%$ appear to indicate that they may consider changes. Of those who may not be content, very few indicated the desire to have more lawn, ranging from 6.6\% in Albuquerque to $1.3 \%$ in Santa Fe. The desire to reduce the extent of lawn is relatively significant in both

\section{LANDSCAPES TYPES, WATER USE, AND UPKEEP COSTS}

(Characteristics typical for New Mexican homes with $2500 \mathrm{ft}^{2}$ of landscapable area)

\section{TYPE A： Traditional Turf Grass Landscape}

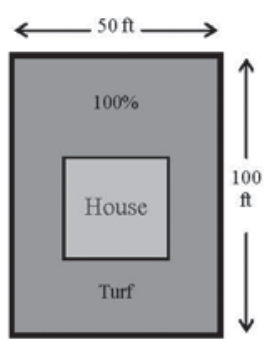

Description: Composed predominantly of high water-using turf grass (bluegrass), shrubs, flowers, gardens, and trees. Characteristics:

Water use: $\quad 40,000 \mathrm{gal} / \mathrm{year}$

Water cost:

Maintenance cost:

$\$ 120 /$ year

Maintenance effort

$\$ 600 /$ year

$150 \mathrm{~h} /$ year

TYPE B: $\quad 1 / 2$ Traditional TURF GRASS, $1 / 2$ WATER CONSERVING

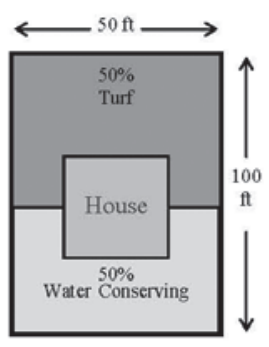

Description: Under this alternative, turf grass area is cut in half and replaced with water-conserving types e.g., some shrubs, flowers, gardens, and drought-tolerant trees. Characteristics:

Water use: $\quad 25,000 \mathrm{gal} /$ year

Water cost:

$\$ 80 /$ year

Maintenance cost: $\quad \$ 400 /$ year

Maintenance effort $\quad 100 \mathrm{~h} /$ year

TYPE C： 1/4 Traditional T URF GraSs, 3/4 WATER-CONSERVING

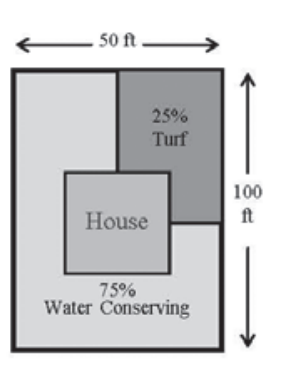

Description: Under this alternative, turf grass area is cut by $75 \%$ and replaced with water-conserving types e.g., some shrubs, flowers, gardens, and drought-tolerant trees. Characteristics:

Water use: $\quad 20,000 \mathrm{gal} /$ year

Water cost:

Maintenance cost:

Maintenance effort

$\$ 60 /$ year

$\$ 250 /$ year

$50 \mathrm{~h} /$ year

TYPE D: NO TURFGRASS, $100 \%$ WATER-CONSERVING

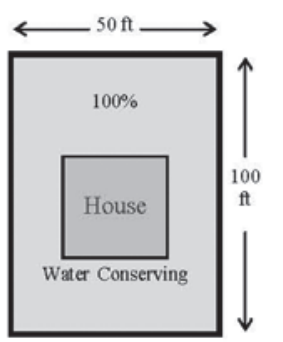

Description: Under this alternative, there is no turf grass, only $100 \%$ water-conserving types including drought-tolerant shrubs, flowers, trees, native vegetation, and rocks. Characteristics:

Water use:

Water cost:

Maintenance cost:

Maintenance effort

$15,000 \mathrm{gal} /$ year

$\$ 50 /$ year

$\$ 100 /$ year

$25 \mathrm{~h} /$ year

Fig. 3. An example of the alternative landscape choices and characteristics provided to New Mexico homeowners in the 2004 survey $\left(1 \mathrm{ft}^{2}=0.0929 \mathrm{~m}^{2} ; 1 \mathrm{ft}=\right.$ $0.3048 \mathrm{~m}$; 1 gal $=3.7854 \mathrm{~L})$.

Albuquerque and Las Cruces, with at least $15 \%$ of homeowners indicating such a desire. As might be expected, given the much lower extent of lawn in Santa Fe, less than 3\% of homeowners expressed a desire to reduce lawns.

To examine landscape preferences more closely, homeowners were asked to consider four general residential landscape configurations that varied the shares planted to turfgrass and to water-conserving plants and rocks (an example of this exhibit is shown in Fig. 3). Homeowners estimated which type most closely resembled the current configuration of their landscape. They were then asked to identify the configuration that they most preferred for both their home and for areas surrounding public buildings. Shown in Table 4, homeowners indicated that more than $75 \%$ had already less than one-quarter 
Table 4. The current and preferred landscape types for homes and public buildings reported in a 2004 survey of urban New Mexico homeowners.

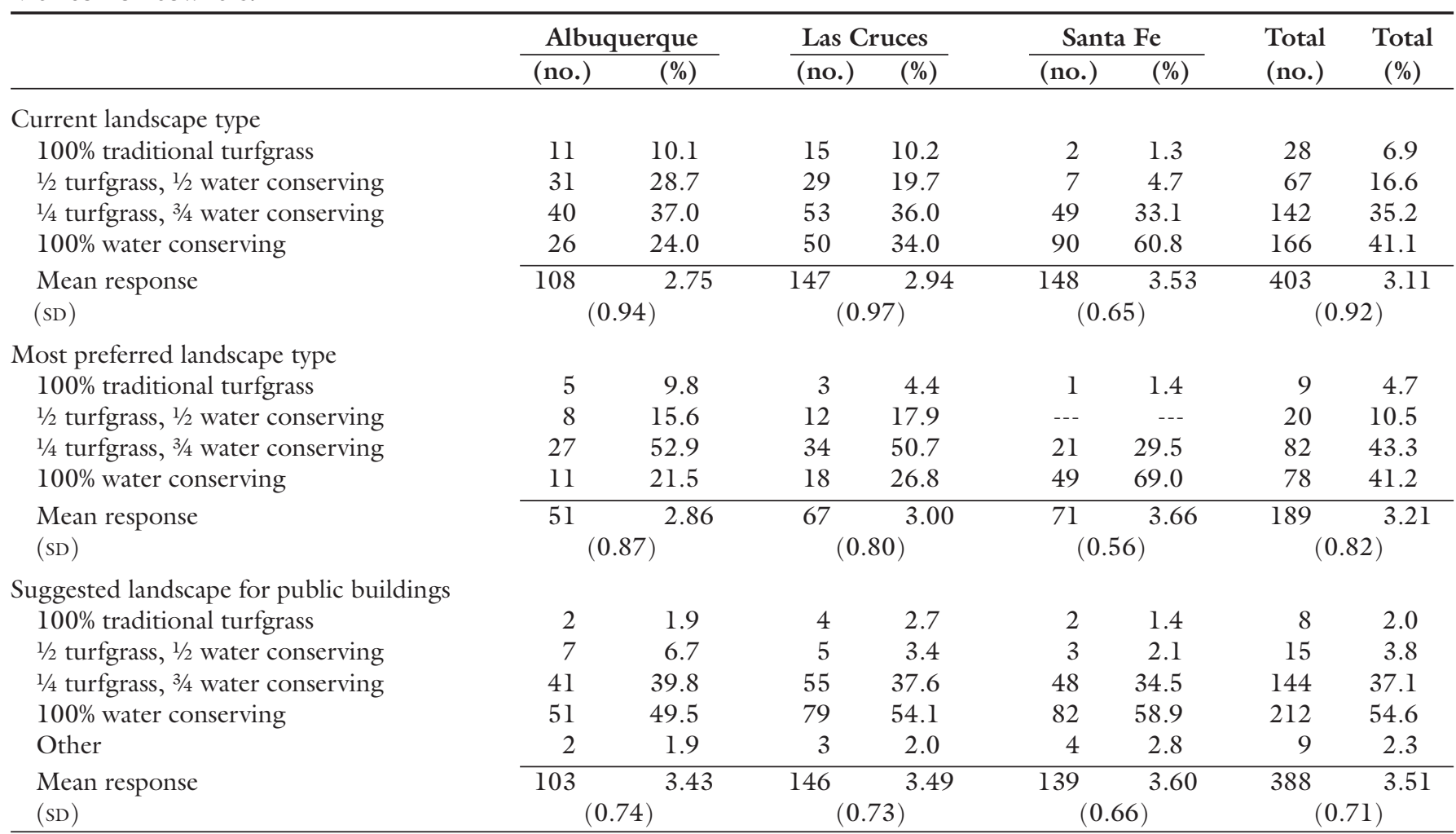

turfgrass compared to about $85 \%$ that desired this configuration. As for public buildings, the frequency of responses for one-quarter or less in turfgrass climbed further to $92 \%$. It appears the demand for climate-appropriate, water-conserving landscapes is quite widespread and consistent with an even stronger level of support found in the community of Santa Fe.

When given the opportunity to identify income and time as limiting the realization of their preferred landscapes, $25 \%$ and $12 \%$ of homeowners indicated these as barriers, respectively. Figures 4 and 5 compare these estimates across the communities, and indicate that Albuquerque and Las Cruces homeowners are more likely to be constrained by both income and time than Santa Fe homeowners. Recognizing that importance of these barriers, some communities are using financial incentives to reduce their magnitude. For example, Albuquerque began a "turfgrass to xeriscape" conversion program in 1996 that (in 2004) paid qualified homeowners $\$ 0.40 / \mathrm{ft}^{2}$ of bluegrass removed and replaced by xeriscape up to $2000 \mathrm{ft}^{2}(\$ 800)$, and requires recipients to replace sprinkler irrigation with an efficient system such as drip, soaker or bubbler. Awareness

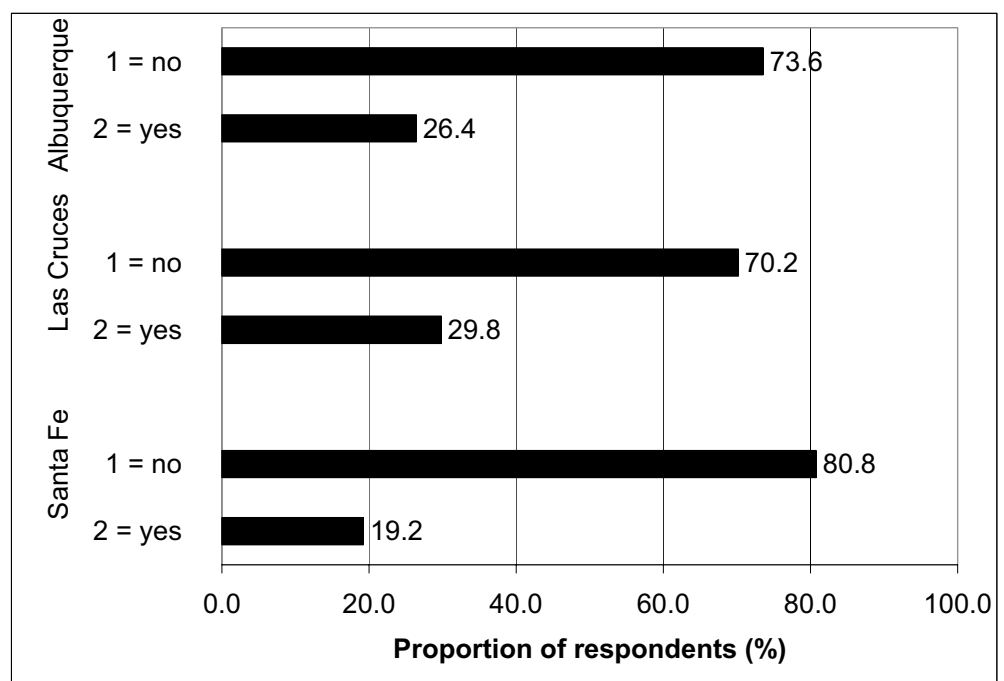

Fig. 4. The importance of money and income as barriers to New Mexico homeowners in changing their landscapes to those they would prefer. An affirmative response $(2$ " "yes") indicates the perception of a barrier.

of the program was indicated by only $40 \%$ of Albuquerque respondents. Neither Las Cruces nor Santa Fe currently offers such a turfgrass conversion program-though such programs are under active consideration. Santa Fe has a rebate program for water-efficient appliances that could explain the small percentage $(<3 \%)$ who indicated program awareness there.
IMPORTANCE OF INFORMATION, MEDIA, COSTS, AND OTHER PROGRAM FACTORs. What are the important factors affecting landscape choices? Homeowner's were asked to rate several potential factors on a scale from $\mathrm{l}=$ "not very important" to 5 = "very important." Aesthetic concerns, water cost, and news reports regarding water scarcity were most highly rated with 


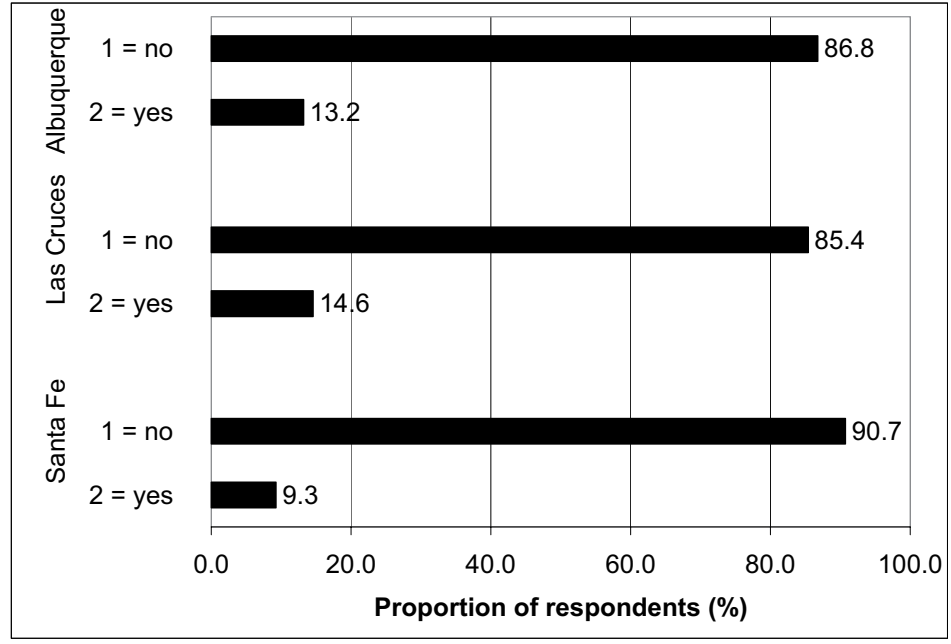

Fig. 5. The importance of time as a barrier to New Mexico homeowners in changing their landscapes to those they would prefer. An affirmative response (2 $=$ "yes") indicates the perception of a barrier.

average scores of 3.8 or 3.9. Enhancing neighborhood character averaged 3.2 and community programs averaged 2.7. There were no strong trends in the responses from the different communities regarding the importance of factors. It is interesting to note that homeowners clearly perceived water cost as more important than community programs in their consideration of landscape choice. This suggests that residents are more aware of their water rates than community conservation efforts. However, the extent to which water rates actually influence landscape decisions remains questionable. This finding may lend support to the use of conservation type, water-rate schedules that include, for example, variable block rates that are increasing with the quantity used and conditioned upon existing supply conditions [i.e., the marginal rates (especially the higher ones) could be raised during drought emergencies].

It is also interesting to note that about $15 \%$ of respondents noted the importance of "other factors." Examples of these factors include: ease of maintenance, cost of landscaping, labor and materials, effect on property value, efficacy in conserving water, and creation of habitat for wildlife.

Nearly 15\% of homeownersacross all three communities-indicated a desire to learn more about landscape possibilities and changes. This is quite a positive finding that suggests there is broad interest in seeking advice on landscape choices, and perhaps indicates a sizable interest for extension programs that support landscape education. It is also a positive finding that only one respondent indicated that a choice to reduce the amount of lawn would not be accepted by their neighbors. This suggests that community covenants, codes, and restrictions are not likely to be a significant barrier to adopting water-efficient landscapes. It is also interesting to note that the gap observed by Spinti et al. (2004) between potential and actual adopters is also approximately $25 \%$.

\section{Conclusions}

With continued population growth, New Mexico communities will be increasingly challenged to meet their growing water needs. These challenges are likely to be met with efforts not only to secure additional supplies but also to balance these supplies with programs and policies that encourage conservation and increase water use efficiency. Based on the limited sample of this study, there are strong indications that New Mexico's residents are increasingly mindful of these challenges and may be growing in their preparedness to shoulder responsibility for stewarding the state's water resources.

Key findings suggest:

- Household awareness, responsibility, and behavior regarding water conservation are and can be further affected by both economic and noneconomic aspects of water conservation programs.

-There is broad community support to limit turfgrass and increase the areas planted to native, natural, and water-conserving landscapes.

- Household awareness and responsibility are community assets that should be nourished through extension and community educational programs.

-Evidence showing that $40 \%$ are not "content" with their current landscape suggests that significant impediments remain and limit still greater adoption of water-conserving landscapes.

The study demonstrates that program effectiveness is possible to measure and track over time with limited resources. Measuring performance is important for public institutions that are entrusted not only with the management and planning for New Mexico's natural resources but that are entrusted with fiduciary responsibilities and are accountable to taxpayers and ratepayers who ultimately underwrite public water conservation programs.

\section{Literature cited}

Addink, S. 2005. Cash for grass: A cost effective method to conserve landscape water? Univ. Calif. Riverside Turfgrass Res. Facility, Riverside.

Dillman, D.A. 2000. Mail and internet surveys: The tailored design method. 2nd ed. Wiley, New York.

Ferguson, B.K. 1987. Water conservation methods in urban landscape irrigation: An exploratory overview. Water Resource Bul. 23:147-152.

Hurd, B.H. and J. Smith. 2005. Landscape attitudes and choices: A survey of New Mexico homeowners. N.M. State Univ. Water Task Force, Las Cruces.

Knopf,J. 2003. Water wise landscaping with trees, shrubs and vines: A xeriscape guide for the Rocky Mountain region. Chamisa Books, Boulder, Colo.

Sovocool, K.A. 2005. Xeriscape conversion study: Final report. Southern Nevada Water Authority, Las Vegas.

Spinti, J.E., R. St. Hilaire, and D. Van Leeuwen. 2004. Balancing landscape preferences and water conservation in a desert community. HortTechnology 14:72-77. 